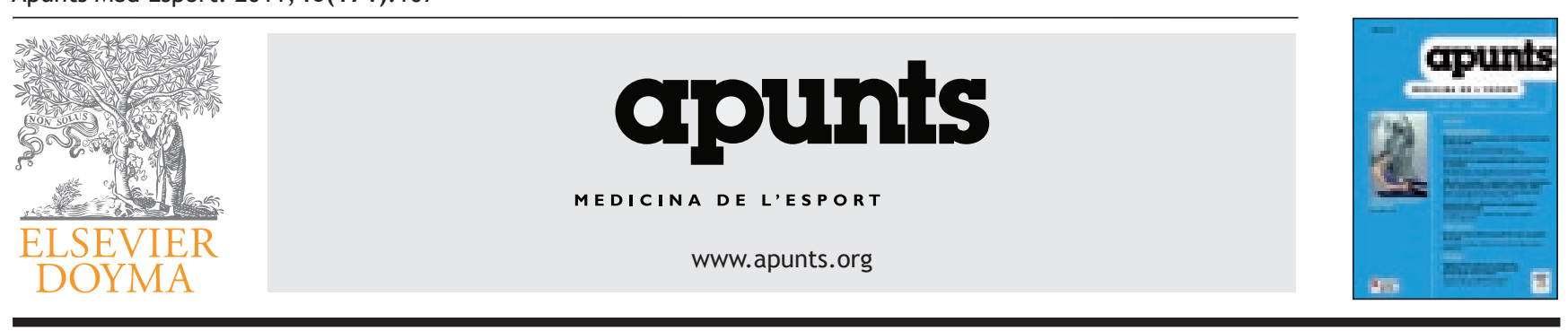

EDITORIAL

\title{
APUNTS. MEDICINA DE L'ESPORT: una revista internacional
}

\section{APUNTS. MEdicina DE L'EsPort: an international journal}

\section{R. Balius}

Editor, Apunts. Medicina de l'Esport

Hoy en día podemos decir sin temor a equivocarnos que la revista Apunts. Medicina de l'Esport es una revista referente en medicina del deporte en el área latinoamericana. El comité editorial está especialmente orgulloso del alto número de originales que este año 2011 están llegando a nuestra redacción. Contamos con artículos de distintos puntos de Latinoamérica con calidad suficiente para ser publicados en nuestra revista. Argentina, Colombia y Cuba son algunos de los países que aportan artículos de forma notable y continuada. Lamentablemente, Apunts no puede aceptar todos los artículos que llegan, puesto que su cabida en ella es limitada, a pesar de tratarse de una revista electrónica.

Pero no solo Apunts es visible en esta área, sino que de forma lenta y progresiva está siendo considerada en otros lugares del mundo. Así, en el pasado número de la revista el Dr. Kenneth R. Kaufman y colaboradores, de los Departments of Psychiatry, Neurology and Anesthesiology, UMDNJ-Robert Wood Johnson Medical School, de New Brunswick (New Jersey, EE.UU.), presentaron el trabajo “Attention-deficit/hyperactivity disorder (ADHD) in gymnastics: preliminary findings"'. El hecho de que autores estadounidenses cuenten con Apunts como una opción real para publicar sus investigaciones refleja la buena salud de que goza nuestra revista.

Igualmente, en lo que va de año hemos recibido artículos de muy distintas procedencias: China, Francia y Portugal ilustran este fenómeno. Así, en el número que hoy presentamos damos la bienvenida al Dr. Rahman Rahimi et al., del Department of Physical Education and Sport Science, University of Kurdistan (Sanandaj, Iran), que aporta un original sobre "Effects of very short rest periods on testosterone to cortisol ratio during heavy resistance exercise in men"2.

Todo ello contribuye a que Apunts empiece a ser citada de forma habitual por otras revistas. Si bien todavía falta

\footnotetext{
*Correo electrónico: rbalius@gencat.cat
}

muchísimo para que esto sea una realidad fecunda, el comité de redacción ha observado que el pasado año 2010 había empezado la citación de Apunts, y que esta tendencia se mantiene durante este año 2011. Ello es debido no solo a que la revista es más visible, sino que además la calidad de los trabajos ha mejorado de manera sustancial.

Todas estos hechos animan a este comité de redacción a continuar trabajando para que Apunts. Medicina de l'Esport alcance la máxima notoriedad posible tanto a nivel estatal como internacional. Para ello sería conveniente mantener la revista bilingüe (catalán y español) y añadir en un futuro no muy lejano la versión completa en inglés de la misma. De esta forma Apunts conseguiría dos objetivos. Por un lado, aumentar la visibilidad de la revista de forma definitiva. Por otro lado, que la revista tenga su versión inglesa facilita que los investigadores, tanto de Cataluña como del resto del Estado español y también de Latinoamérica, den a conocer su producción científica al mundo.

Si se consigue mantener la revista en la línea que recientemente ha tomado e incorporamos la necesaria traducción al inglés, seremos visibles tanto en Latinoamérica como en el mundo anglosajón. Creemos que de esta forma Apunts aumentará y consolidará su número de citas. Esto es justamente lo que objetiva la importancia de una revista científica.

\section{Bibliografía}

1. Kaufman KP, Bajaj A, Schiltz JF. Attention-deficit/hyperactivity disorder (ADHD) in gymnastics: preliminary findings. Apunts Med Esport. 2011;46:89-95

2. Rahimi R, Rohani H, Ebrahimi M. Effects of very short rest periods on testosterone to cortisol ratio during heavy resistance exercise in men. Apunts Med Esport. 2011. doi:10.1016/j. apunts.2011.03.002 